\title{
Health Disparities: Challenges, Opportunities, and What You Can Do About It
}

Oopen acess

${ }^{1} \mathrm{MD}, \mathrm{MPH}$. Adjunct Professor

Department of Epidemiology. Rollins

School of Public Health

Emory University. Atlanta, USA.

\section{Corresponding author:}

hatrash@emory.edu

Manuscript received: May 2018

Manuscript accepted: September 2018

Version of record online: November 2018

\begin{abstract}
Racial disparities in health outcomes, access to health care, insurance coverage, and quality of care in the United States have existed for many years. The Development and implementation of effective strategies to reduce or eliminate health disparities are hindered by our inability to accurately assess the extent and types of health disparities due to the limited availability of race/ethnicity-specific information, the limited reliability of existing data and information, and the increasing diversity of the American population. Variations in racial and ethnic classification used to collect data hinders the ability to obtain reliable and accurate health-indicator rates and in some instances cause bias in estimating the race/ethnicity-specific health measures. In 1978, The Office of Management and Budget (OMB) issued "Directive 15" titled "Race and Ethnic Standards for Federal Statistics and Administrative Reporting" and provided a set of clear guidelines for classifying people by race and ethnicity. Access to health care, behavioral and psychosocial factors as well as cultural differences contribute to the racial and ethnic variations that exist in a person's health. To help eliminate health disparities, we must ensure equal access to health care services as well as quality of care. Health care providers must become culturally competent and understand the differences that exist among the people they serve in order to eliminate disparities. Enhancement of data collection systems is essential for developing and implementing interventions targeted to deal with population-specific problems. Developing comprehensive and multi-level programs to eliminate healthcare disparities requires coordination and collaboration between the public (Local, state and federal health departments), private (Health Insurance companies, private health care providers), and professional (Physicians, nurses, pharmacists, laboratories, etc) sectors.
\end{abstract}

Keywords: health disparities, access to care, data collection, quality of care. 


\section{INTRODUCTION}

The disproportionate burden of poor health status and premature mortality among certain segments of the United States population, often referred to as health disparity, has been well documented for over two centuries. Many studies have documented widespread racial and ethnic disparities in health status and the many factors that contribute to these disparities: inequalities in income and education, environmental and economic conditions, specific health behaviors and lifestyle patterns, access to care, and even quality of services. Racial and ethnic disparities have been observed in life expectancy as well as healthy life expectancy as far back as the year 1900 and as recently as $2015^{1,2}$. Health disparities have also been observed in other segments of the population characterized by geographical location, age, gender, disability status, and sexual orientation.

This paper presents an overview of existing United States race/ethnicity-specific health statistics including statistics on mortality, morbidity, behaviors, health care utilization, disability, and quality of care. The paper also discusses the current systems used to classify people by race/ethnicity and their limitations; factors that contribute to health disparities and the challenges facing program and policy makers in dealing with the issue of health disparity; the various strategies that have been developed to reduce or eliminate health disparities; and the roles that health care providers can play in reducing or eliminating health disparities.

\section{Challenges}

Several challenges face program managers and policy makers in understanding health disparities and being able to develop and implement effective strategies to reduce or eliminate such disparities. These challenges start with a limited ability to accurately assess the magnitude and types of problems because of issues related to the reliability of data and information. They are further complicated by the increasing diversity of the American public both in racial and ethnic composition, the variation within each racial or ethnic group by health status, and the various factors that contribute to good or poor health status, such as socioeconomics, environment, education, culture and other factors.

\section{Increasing Diversity of the American Public}

During the past 50 years, the diversity of the United States population has increased. The proportion of White Americans decreased from $83.2 \%$ in 1970 to $64 \%$ in 2010 ; the proportion of Blacks increased from $11.1 \%$ in 1970 to $12.6 \%$ in 2010 , and the proportion of Hispanics living in the United States increased from $4.7 \%$ in 1970 to $16 \%$ in $2010^{3}$. However, the U.S. Bureau of the Census projects that by 2060 , Whites will constitute only $44 \%$ of the total population of the United States. Most of the increase in the American population is due to increases among minority population, particularly Hispanics. The Asian population is projected to be the fastest-growing group (second only to individuals with mixed races); this population is expected to increase from $5.4 \%$ in 2014 to $9.3 \%$ in 2060 , whereas the Hispanic population is expected to increase from
$17 \%$ in 2014 to $29 \%$ in 2060 , and the Black population is expected to increase from $13 \%$ in 2014 to $14 \%$ in 2060 . American Indian, Alaska Native, Native Hawaiian and Other Pacific Islander populations are expected to see modest growth and continue to account for a very small segment of the population ${ }^{4}$.

Concurrent with this increased population diversity, there has been an increase in the numbers of interracial marriages, resulting in an increase in the number of people born who are of mixed race or ethnicity. The "Two or More Races" population is projected to be the fastest growing segment of the US population; the proportion of individuals reporting two or more races is expected to increase from $2.5 \%$ in 2014 to $6.2 \%$ in $2060^{4}$.

\section{Data Collection}

Data used to calculate health status indicators and health care utilization measures are obtained from multiple sources collected by various agencies at the local, state, and federal levels. Categories and types of information collected include natality, mortality, morbidity, health behavior and attitude, health service utilization, health care financing, population size, and migration, as well as socioeconomic data ${ }^{5}$. Although data are collected by different agencies and from different sources, these data often need to be combined to estimate health-related indicators, such as using vital statistics and census data to estimate birth and death rates. Because these sources may use different methods to determine the race and ethnicity of individuals, substantial inconsistencies can result in the categorization for race and ethnicity in data collection and reporting. For example, information regarding race and ethnicity in the census depends on self-identification, which can differ from race and ethnic categorization assigned by an interviewer or reported by a health care provider $^{3,5}$.

\section{Race and Ethnicity Classification}

The ability to obtain reliable and accurate healthindicator rates for racial and ethnic groups in the United States has been seriously limited by the lack of clear guidance for classification and categorization and using agency-specific systems to collect data. The terminology used to classify the American public by race and ethnicity has changed over the years to be more consistent with current language and as a result of emerging changes in the composition of the population. The first census of the United States in 1790 enumerated three racial groups: Whites, Blacks, and "Civilized Indians"- those who paid taxes ${ }^{6}$. During the 1800s and early 1900s, census and vital statistics reports classified the American public as White, Black, and Other Colored (Other Colored included Indians, with a few Chinese and Japanese) ${ }^{7}$. New racial categories were added in the late 19th century and beyond (Chinese in 1870, Japanese in 1890) as the need arose to track new immigrant groups ${ }^{6}$. The growth of the Hispanic population in the United States starting in the early 1970 s stimulated interest in obtaining vital statistics information pertaining to that group. In 1978, the U.S. Office of Management and Budget (OMB) issued "Directive 15", 
entitled "Race and Ethnic Standards for Federal Statistics and Administrative Reporting". OMB revised Directive 15 in October 1997. The revised standards recommend the use of a minimum of five categories for data on race and two categories on ethnicity. The race categories are: American Indian or Alaska Native, Asian, Black or African American, Native Hawaiian or Other Pacific Islander, and White. The categories for data on ethnicity are: "Hispanic or Latino" and "Not Hispanic or Latino".

\section{Data Accuracy and Reliability}

Studies have repeatedly demonstrated that a proportion of non-Black minorities are misclassified as White on death certificates. This numerator problem leads to an underestimate of the death rates for American Indians, Asian and Pacific Islanders, and Hispanics ${ }^{9}$. Additional bias in the reliability of health indicators for minority populations is related to the considerable heterogeneity within each of the major racial or ethnic populations, with significant variation in health status within each group. Moreover, a relatively high proportion of Hispanics and other minorities, especially Asian Americans, are foreign born, and their health profile reflects in part the impact of immigration. Immigrants tend to enjoy better health status than the native-born population, even when those immigrants are lower in socioeconomic status ${ }^{10}$. However, with increasing length of stay in the United States and adaptation to mainstream behavior, the health status of immigrants in lower socioeconomic status deteriorates.

\section{Misclassification}

Until the introduction of OMB's Directive 15 in 1978 (and its revision in 1997, 2000 and 2007), the methods used to assign race or ethnicity to people, deaths and births were not consistent and, therefore, could cause a bias in estimating the race- and ethnicity-specific birth and death rates. Race classification of births is based on information provided by the family or based on observation; race classification for deaths is recorded by a funeral director based on information provided by an informant or based on observation; however, information on population in the census by race and/or ethnicity is based on information collected through self reports of people who respond for themselves or others in their household ${ }^{6}$.

\section{Potential Bias}

The multiple sources of data, together with the multiple means for classifying people by race and ethnicity, have resulted in biases when data sources are combined to estimate health indicators for the various racial and ethnic groups. Studies showed greater than $98 \%$ agreement in reporting race on death certificates and other sources for White and Black decedents, but poorer agreement for other groups ${ }^{6,11}$. Thus, the quality, reliability, and accuracy of death rates by race and Hispanic origin vary among population groups. Generally, death rates are reliable for the White and Black populations and the overall effect of Black and White undercounts does not seriously distort analysis or interpretation of the resulting mortality data. However, for the other minority population groups, levels of mortality are seriously biased from misreporting in the numerator and under-coverage in the denominator of the death rates.

\section{Health Status Indicators / Measures of Health Disparity}

The number of measures of health status, health outcomes, behaviors, access, and quality of care is unlimited, and it is hard to decide which health indicators to use for comparing health status among the various segments of the population. To compare health status of various population groups, in addition to mortality rates, we examined health indicators developed by the U.S. Department of Health and Human Services (DHSS) to monitor the health of the nation: the "Healthy People 2000" health status indicators and the "Healthy People 2010" leading health indicators which were developed to facilitate the comparison of health status measures at the national, state, and local levels ${ }^{12,13}$.

\section{Mortality}

Maternal, infant, general, and age adjusted mortality rates continue to be higher for Blacks than for Whites ${ }^{1,14,15}$. Since 1900 , the life expectancy at birth has remained better for Whites than for Blacks. In 2015, Hispanic males and females had the longest life expectancy at birth (79.3 and 84.3, respectively) and nonHispanic black males (71.8) and females (78.1) had the shortest. For whites, life expectancy at birth was 76.3 years for males and 81.1 years for females ${ }^{14}$. In 2014, the infant mortality rate among blacks was 10.93 infant deaths per 1,000 live births compared with 4.9 among whites and 5.0 among Hispanics ${ }^{14}$. In 2015, Blacks had an overall age-adjusted death rate that was 1.16 times higher than that of the White population (876.1 deaths per 100,000 compared with 753.2 for whites). The overall death rate for Hispanics was lower than that for Whites (525.3 deaths per 100,000$)^{14,16-18}$. In 2015 , elevated mortality rates for Blacks compared to the White and Hispanic populations existed for most of the 10 leading causes of death. Blacks experienced the highest rates of mortality from heart disease, cancers, influenza and pneumonia, cerebrovascular disease (including stroke), HIV/AIDS, diabetes, motor vehicle-related injuries, kidney disease, and homicide than any other racial or ethnic group. Hispanics had higher death rates than Whites and blacks for chronic liver disease and cirrhosis, whereas whites had higher death rates than Blacks and Hispanics for chronic lower respiratory diseases, Alzheimer's disease, unintentional injuries, poisoning and suicide ${ }^{14}$.

\section{Disability}

The U.S. Census Bureau reported that there were 56.7 million people with some type of long-lasting condition or disability in the United States in 2010. This represents $18.7 \%$ of the U.S. population. The ageadjusted rates of disability varied among the various racial and ethnic groups, ranging from 14.5\% among Asians to $17.4 \%$ among Whites, $17.8 \%$ among Hispanics, and $22.2 \%$ among Blacks ${ }^{19}$. 


\section{Morbidity and Health Status}

When asked to assess their own health and the health of family members living in the same household, a much higher proportion of Whites than Blacks or Hispanics assessed their health as excellent or very good. For selected morbidity measures, in 2011-2014, Blacks had higher reported incidence rates than Whites for HIV/AIDS, tuberculosis, syphilis, diabetes, and childhood asthma. Higher rates of tuberculosis were also reported among the other minority groups, with the highest rate of tuberculosis being among the Asian/Pacific Islander population ${ }^{20}$. In 1998, it was estimated that the highest proportion of people living in counties with poor air quality were Hispanics and Asians/Pacific Islanders (60\%); obesity was most common among adolescent and adult male and female Blacks as well as among adolescent Hispanics; Blacks, Hispanics and American Indians/Alaska Natives had higher rates of births to mothers 10-17 years of age than Whites and Asians/Pacific Islanders ${ }^{21,22}$. Other health status indicators reported in 2014 indicated that Blacks were most likely of all racial and ethnic groups to report that they were in fair or poor health and most likely to have ever been told by a health care professional that their blood pressure was high. American Indians/Alaska Natives were most likely to be obese; Whites were most likely to have ever been told by a health care professional that their blood cholesterol level was high; and Blacks and American Indians/Alaska Natives were most likely to have ever been told by a health care professional that they had diabetes ${ }^{20}$.

\section{Health Care Utilization and Access to Care}

Rates of utilization of health care are different among the different minority populations. For example, in 2016, a higher proportion of White mothers received early prenatal care than black and Hispanic mothers ${ }^{23}$. Whites also had the highest proportion of children receiving all recommended vaccines, adults 65 years of age or older vaccinated against influenza, adults ever vaccinated against pneumococcal disease, people having health insurance, and people having a specific source of ongoing health care ${ }^{20}$. For 2013-2014, whites were more likely to have a usual source of care, less likely to delay receipt of medical care, and more likely to have visited a doctor's office, emergency department, or had a home visit by a health care provider during the past 12 months $^{20}$. In 2014, whites were also more likely than Blacks and Hispanics to have received the Combined 7-vaccine series, the DTP/ DT/DTaP, polio, measles, mumps, rubella, HiB, Hepatitis B, Hepatitis A, Varicella, PCV, influenza, pneumococcal, and Rotavirus vaccines ${ }^{20}$. A higher proportion of Whites than Blacks and Hispanics received preventive care visits including having a pap smear within the past 3 years, having a mammogram (for women older than 50 years of age) in the past 2 years, having a clinical breast examination (for women older than 50 years of age) in the past 2 years, having a home-kit fecal occult blood test (for people 50 or older 50 ), and having had a sigmoidoscopy (for people 50 years of age or older) ${ }^{20}$. In 2016, Whites had the lowest uninsured rate; the uninsured rates for Blacks and Hispanics were higher than for whites. Hispanics had the highest uninsured rate ${ }^{24}$.

\section{Health Care Disparity}

Recently, concern has grown that even at equivalent levels of access to care, racial and ethnic minorities experience a lower quality of health services and are less likely to receive even routine medical procedures than White Americans. For example, Blacks with endstage renal disease are less likely to receive peritoneal dialysis and kidney transplantation, Blacks and Hispanic patients with bone fractures seen in hospital emergency departments are less likely than Whites to receive analgesia, and, Black Medicare patients with congestive heart failure or pneumonia received poorer quality care than Whites. Moreover, a growing number of studies have found racial differences in the receipt of major therapeutic procedures for a broad range of conditions, even after adjusting for insurance status and severity of disease, including situations in which differences in economic status and insurance coverage are minimized such as the Veterans Health Administration System and the Medicare $\operatorname{program}^{25}$.

Concerned about the increasing reports of disparities in health care, Congress in 1999 requested the Institute of Medicine (now the National Academies of Sciences, Engineering, and Medicine) to assess disparities in the kinds and quality of health care received by US racial and ethnic minorities and non-minorities. The Institute of Medicine's Committee on Understanding and Eliminating Racial and Ethnic Disparities in Health Care (the committee) defined health care disparities as "racial and ethnic differences in the quality of health care that are not due to access-related factors or clinical needs, preferences, and appropriateness of intervention". The committee examined many sources of data to assess the scope of disparities in health care, explore sources of these disparities, and generate strategies to eliminate them. Data sources included a review of the recent literature, commissioned papers, public input from professional societies and organizations, input from technical liaison panels, and focus groups and roundtable input. The committee concluded that racial and ethnic disparities in health care are, with few exceptions, remarkably consistent across a range of illnesses and health care services. These disparities are associated with socioeconomic differences and tend to diminish significantly and, in a few cases, disappear altogether when socioeconomic factors are controlled. The majority of studies reviewed by the committee, however, found that racial and ethnic disparities remained even after adjustment for socioeconomic differences and other health care access-related factors ${ }^{25}$.

\section{Contributors}

Racial and ethnic variations in health result from variations in people's exposures or vulnerability and reflect issues related to the health care system. At the individual or community level, factors that contribute to variations in health include behavioral and psychosocial factors, material factors (such as education, occupation, income, and wealth), and environmental living conditions and resources. Health system factors include issues of access to health care systems (such as physical access, financial access, and practical access such as user friendliness), 
access to services within the system (getting appointments, completing referrals to specialists, and getting after-hours advice), health services utilization, health care quality, and the ability of the system and providers to address patients' needs (awareness of patients' conditions and functional limitations, knowledge and clinical skills, and cultural competence). These factors are interdependent, affect one another to a large extent, and often are driven by socioeconomics.

\section{Socioeconomics}

Being in a lower socioeconomic class usually means poorer housing conditions, fewer opportunities for higher education, less health insurance coverage, and lower access to health care. Furthermore, environmental health risks such as housing degradation; air, water and soil pollution; and other physical hazards are more prevalent in low-income racial and ethnic minority communities. Individual risk factors for poor health are pronounced among many racial and ethnic minorities; moreover, these risks are confounded by the disproportionate representation of minorities in the lower socioeconomic classes, as well as in hazardous and low paying occupations.

\section{Culture and Acculturation}

Cultural factors also play a role in health disparities; for example, among some immigrant Hispanic populations, birth outcomes have been found to be better than among those of their U.S.-born peers, suggesting that sociocultural risk increases with subsequent generations living in the United States. For example, even though Mexican Americans tend to be poorer, less educated, and medically underserved compared with Whites, they are as healthy as Whites. Mexican American rates of infant mortality and low birth weight are equivalent to Whites and half that of Blacks and the overall mortality among Mexican Americans is lower than that among Whites ${ }^{14,26}$. Mexican Americans also have low rates of lung cancer, heart disease, and chronic respiratory disease. Researchers have referred to this phenomenon as a "paradox", as this observation is contrary to the historical assumptions that increased risk associated with ethnicity has been explained in terms of genetic differences related to race or factors related to SES. In 1989, Scribner, in a study of low birth weight among Mexican Americans, proposed that factors associated with Mexican cultural orientation might be protective against the risk of low birth weight among Mexican Americans. Scribner further suggested that "acculturation" could explain the paradox of better health among Mexican immigrants and deteriorating health among Mexican Americans. Mexican American ethnicity is a marker of a Mexican cultural orientation that is defined by behavioral norms that can account for their favorable health status. Mexican Americans as a group smoke less, drink less, and eat a better diet than do Whites. Over time, and once Mexican Americans have been fully acculturated in the high-risk environments of the socioeconomically disadvantaged communities, their behavioral norms and health outcomes will resemble those of other socioeconomically disadvantaged groups living in similar community environments ${ }^{27,28}$.

\section{Racism and Racial Discrimination}

Racism, according to Webster's dictionary is defined as "a belief that race is the primary determinant of human traits and capacities, and that racial differences produce an inherent superiority of a particular race" ${ }^{29}$. Jones offers a simplified framework for understanding racism and how it affects health outcomes. She proposes that racism exists at three levels: institutionalized, personally mediated, and internalized. Institutionalized racism manifests itself both in material conditions (e.g., differential access to quality education, sound housing, gainful employment, appropriate medical facilities, and a clean environment) and in access to power (e.g., differential access to information, resources and voice - including voting rights, representation in government and control of the media). Institutionalized racism is often evident as inaction in the face of need. Personally-mediated racism is defined as prejudice (differential assumptions about the abilities, motives, and intentions of others based on their race) and discrimination (differential actions toward others based on race). Personally-mediated racism can be intentional and unintentional and includes acts of commission as well as acts of omission. Personally-mediated racism manifests itself as lack of respect (such as poor or no service or failure to communicate options), suspicion (for example shopkeepers' vigilance and everyday avoidance, including street crossing, purse clutching, and standing when there are empty seats on public transportation), and devaluation (surprise at competence, stifling of aspirations, scape-goating, and dehumanization). Finally, internalized racism is the acceptance by members of the stigmatized races of negative messages about their own abilities and intrinsic worth, characterized by their not believing in others who look like them and not believing in themselves. Internalized racism manifests as an embracing of "Whiteness", self-devaluation, and resignation, helplessness, and hopelessness ${ }^{30}$.

\section{Psychosocial Factors}

Some researchers propose that psychosocial factors (health behaviors, stress in family, residential and occupational environments, social integration and support, perception of mastery and control, social ties, and attitudinal orientations) represent critical links between social structure and health status. The social distribution of these factors represents the patterned response of social groups to the realities and constraints of the external environment imposed on them by social structure. Intervening mechanisms between social structure and health status are adaptive to the living and working conditions of the poor. Accordingly, efforts to change the lifestyles of the poor without also altering social structure and life chances not only might be ineffective, but also might do more harm than good. It has been reported that health education campaigns achieve only limited success and are more effective in producing behavior change in higher socioeconomic persons than in their lower socioeconomic peers. For example, cigarettes are widely believed to alleviate stress and tension; lower socioeconomic people face more stress and have fewer resources to cope with it than their better educated peers - thus strategies to get people to quit smoking could be much more complex among minority populations ${ }^{31}$. 


\section{Access to Care}

Another factor that contributes to health disparity is the limited access to health care. Racial and ethnic minorities are less likely than Whites to possess health insurance coverage and, even when insured, can face additional barriers to care due to other socioeconomic factors (such as high co-payments, geographic factors, and insufficient transportation). For example, for children with special health care needs during 1994-1995, Newacheck et al found that minority children were more likely to be without health insurance coverage, to be without a usual source of care, and to report an inability to get needed medical care ${ }^{32}$. Poverty appears to be a major factor affecting access to care. In 2002, the proportion of people without health insurance for the whole year was much higher for all racial and ethnic groups living in poverty, reaching $42.8 \%$ for poor Hispanics. Several other factors contributed to having health insurance: gender, age, nativity, household income, education, and work experience. In each case, people living in poverty were much more likely to have no health insurance for the entire year than the general public with similar characteristics $^{32}$.

\section{Health Care}

Lower quality care is yet another serious factor that contributes to health disparities. The Institute of Medicine's Committee on Understanding and Eliminating Racial and Ethnic Disparities in Health Care concluded that a range of patient-level, provider-level, and system-level factors might be involved in racial and ethnic health care disparities, beyond access-related factors. At the patient level, minority patients are more likely to refuse recommended services, adhere poorly to treatment regimens, and delay seeking care. However, the committee concluded that racial and ethnic differences in patient preferences and care-seeking behaviors and attitudes are unlikely to be major sources of health care disparities. At the health systems level, the ways in which systems are organized and financed, and the availability of services, might exert different effects on patient care, particularly for racial and ethnic minorities. Minority populations have less access to care, independent of their insurance status, because fewer doctors and clinics exist in their communities. Also, where health facilities exist, they might be less well equipped or staffed, or be overcrowded. Moreover, people who are members of minority groups are less likely to be referred for tests, get specialty care or mental health care and needed procedures and surgery. Language barriers, for example, pose a problem for many patients in which health systems lack the resources, knowledge, or institutional priorities to provide interpretation and translation services. Similarly, time pressures on physicians can hamper their ability to accurately assess presenting symptoms of minority patients, especially where cultural or linguistic barriers are present. Several factors can contribute to disparities in health care at the provider level: greater clinical uncertainty when interacting with minority patients; bias (or prejudice) concerning minorities; and beliefs (or stereotypes) held by the provider about the behavior or health of minorities. In deciding on a diagnosis and course of treatment, doctors must balance new information gained from patients and their prior knowledge and expectations about the patients. If physicians have difficulty accurately assessing and understanding the patients' presenting symptoms and condition, they are likely to place greater weight on their prior knowledge and expectations, resulting in an imbalance between treatment decisions and patients' needs. Moreover, there is considerable empirical evidence that even well-meaning Whites who are not overtly biased and who do not believe that they are prejudiced typically demonstrate unconscious implicit negative racial attitudes and stereotypes. Survey research suggests that among White Americans, prejudicial attitudes toward minorities remain more common than not, as over one-half to three quarters believe that relative to Whites, minorities-particularly Blacks-are less intelligent, more prone to violence, and prefer to live off of welfare. The committee concluded that, while there is no direct evidence that provider biases affect the quality of care for minority patients, research suggests that health care providers' diagnostic and treatment decisions, as well as their feelings about patients, are influenced by patient race or ethnicity, and, that the relationship between race or ethnicity and treatment decisions is complex and can also be influenced by the providers' gender, perceptions, and attitudes toward patients, often in subtle ways ${ }^{25}$.

\section{What can we do?}

Health disparities are the product of a multitude of factors including racism, psychosocial, cultural, socioeconomic, environmental, healthcare quality, and policy factors, among others. Many of these factors fall outside the influence of the health care system. Accordingly, the elimination of inequalities in health status ultimately may require changes not only in psychosocial factors (lifestyle characteristics and living conditions) or health care delivery, but also in socioeconomic conditions. Still, health services intervention, whether used alone or in collaboration with social and economic interventions, are likely to play a significant role in reducing racial and ethnic health disparities ${ }^{33}$.

The health care system can start contributing to the elimination of health disparities by working to ensure "equal treatment." The system needs to understand and target population-specific differences in risk factors for illness, develop prevention messages with a specific clinical or population focus, and promote adequate utilization of self-care principles and health promoting services by vulnerable populations. The system should also intensify its efforts to ensure increasing utilization of services by underserved populations by making the system more accessible, responsive, and user-friendly. Steps in that direction include diversifying the health care workforce and acting to improve their cultural competence. Above all, however, the health care system must immediately deal with the issue of disparity in health care.

Educating healthcare providers and making them aware of racial and ethnic disparities in healthcare, and the fact that these disparities exist, often despite providers' 
best intentions, can help alleviate stereotypes, bias, and clinical uncertainty that may influence clinicians' diagnostic and treatment decisions. Cross-cultural training of all current and future healthcare providers can enhance their awareness of how cultural and social factors influence healthcare, while providing methods to obtain, negotiate and manage this information clinically once it is obtained.

Finally, the Institute of Medicine committee made specific recommendations to overcome healthcare disparity: avoiding fragmentation of health plans along socioeconomic lines, training and education of healthcare providers are essential components of the proposed overall strategy, and increasing efforts in collecting data on patient and provider race and ethnicity to allow researchers to better understand factors that are associated with healthcare disparities, help health plans to monitor performance, ensure accountability to enrolled members and payers, improve patient choice, allow for evaluation of intervention programs, and help identify discriminatory practices.

\section{CONCLUSION}

In conclusion, racial and ethnic disparities in health and health outcomes have existed for as long as we had data to measure these outcomes. Serious challenges face health program and policy decision makers in addressing these disparities. The main challenge is the availability and quality of race- and ethnicity-specific data to measure the health and health outcomes in various segments of the population. Another challenge is the fact that health outcomes are the result of many factors (socioeconomic, behavioral, environmental, health care system, education, etc). The health care system does not have the capacity to address all these issues. However, the health care system can reduce these disparities, at least in part, by improving access to health care and the quality of services, understanding risk factors in specific populations and developing and implementing population-specific interventions. It is also extremely important to diversify and improve the cultural competence of the healthcare workforce. In addition, there is an immediate need to educate healthcare providers and make them aware of racial and ethnic disparities in health and health outcomes.

\section{REFERENCES}

1. National Center for Health Statistics. Health, United States, 2016: With Chartbook on Long-term Trends in Health. Hyattsville, MD. 2017.

2. Chang MH, Molla MT, Truman B, Athar H, Moonesinghe R, Yoon PW. Differences in healthy life expectancy for the US population by sex, race/ethnicity and geographic region: 2008. J Public Health. 2015;37(3):470-9. DOI: http://dx.doi.org/10.1093/pubmed/fdu059

3. Humes KR, Jones NA, Ramirez RR, Department of Commerce; Overview of Race and Hispanic Origin: 2010. Census Brief. Census Bureau, 2011.

4. Colby SL, Ortman JM. Projections of the Size and Composition of the U.S. Population: 2014 to 2060. Current Population Reports. Washington: Census Bureau, 2015.

5. Rosenberg HM, Maurer JD, Sorlie PD, Johnson NJ, MacDorman MF, Hoyert DL, et al. Quality of death rates by race and Hispanic origin: a summary of current research, 1999. Vital Health Stat 2. 1999;(128):1-13.

6. Anderson MJ. The american census: a social history. New Haven: Connecticut. Yale University Press, 1988.

7. National Center for Health Statistics. Vital Statistics of the United States 1975. Volume II; Mortality, Part A. Public Health Service. Hysattsville, Maryland, 1979.

8. Executive Office of the President. Office of Management and Budget. Revisions to the Standards for the Classification of Federal Data on Race and Ethnicity. Washington: 1997.

9. Hahn RA. The State of Federal Health Statistics on racial and ethnic groups. JAMA. 1992;267(2):268-71.

10. Williams DR. Race, socioeconomic status and health: The added effects of racism and discrimination. Ann N York Acad Sci. 1999;896(1):173-88. DOI: https://doi.org/10.1111/j.1749-6632.1999.tb08114.x

11. Hambright TZ. Comparability of marital status, race, nativity, and country of origin on the death certificate and matching census record. Vital Health Stat 2. 1969;(34):1-47.

12. Freedman MA. Health Status Indicators for the year 2000. Healthy People 2000 Stat Notes. 1991;1(1):1-4.

13. Maiese DR. Healthy People 2010: Leading health indicators for women. Women's Health Issues. 2002;12(4):155-64. DOI: https://doi.org/10.1016/S1049-3867(02)00140-8

14. National Center for Health Statistics. Health, United States, 2016: With Chartbook on Long-term Trends in Health. Hyattsville: National Center for Health Statistics, 2017.

15. Keppel KG, Pearcy JN, Wagener DK. Trends in racial and ethnic-specific rates for the health status indicators: United States, 1990-98. Healthy People 2000 Stat Notes. 2002;(23):1-16. 
16. QuickStats: age-Adjusted Death Rates, by Race/Ethnicity - National Vital Statistics System, United States, 2014-2015. MMWR Morb Mortal Wkly Rep. 2017;66:375. DOI: http://dx.doi.org/10.15585/mmwr. $\mathrm{mm} 6613 \mathrm{a} 6$

17. Heron M. Deaths: Leading causes for 2013. Natl Vital Stat Rep. 2016;65(2):1-95.

18. Murphy SL, Xu JQ, Kochanek KD, Curtin SC, Arias E. Deaths: Final data for 2015. Natl Vital Stat Rep. 2017;66(6):1-75.

19. Brault MW. Americans with disabilities: 2010. Current Populations Report. 2012; p.70-131.

20. National Center for Health Statistics. Health, United States, 2015: With Special Feature on Racial and Ethnic Health Disparities. Hyattsville: National Center for Health Statistics, 2016.

21. National Center for Health Statistics. Health, United States, 2003. Hyattsville: National Center for Health Statistics, 2003.

22. Grunbaum J, Kann L, Kinchen S, Williams B, Ross JG, Lowry R, et al. Youth Risk Behavior Surveillance-United States, 2001. J School Health. 2002;72(8):313-328. DOI: https://doi.org/10.1111/j.1746-1561.2002.tb07917.x

23. Martin JA, Hamilton BE, Osterman MJK, Driscoll AK, Drake P. Births: Final data for 2016. Natl Vital Stat Rep. 2018;67(1):1-55.

24. Barnett JC, Berchick ER. Health Insurance Coverage in the United States: 2016. Current Population Reports. Washington: Government Printing Office, 2017; p.60-260.

25. Nelson AR. Unequal treatment: confronting racial and ethnic disparities in health care. J Natl Med Assoc. 2002;94(8):666-8.

26. Bolen JC, Rhodes L, Powell-Griner EE, Bland SD, Holtzman D. State-specific prevalence of selected health behaviors, by race and ethnicity - Behavioral Risk Factor Surveillance System, 1997. MMWR CDC Surveill Summ. 2000;;49(2):1-60.

27. Scribner R. Paradox as paradigm--the health outcomes of Mexican Americans. Am J Public Health. 1996;86(3):303-5.

28. Scribner R, Dwyer JH. Acculturation and low birthweight among Latinos in the Hispanic HANES. Am J Public Health. 1989;79(9):1263-7.

29. Merrianm-Webster's collegiate dictionary. 10th ed. Merriam-Webster, Incorporated. Springfield: 2001.

30. Jones CP. Levels of racism: a theoretical framework and a gardener's tale. Am J Public Health. 2000;90(8):1212-15. DOI: http://dx.doi.org/10.2105/AJPH.90.8.1212

31. Williams DR. Socioeconomic differentials in health: a review and redirection. Soc Psychol Quart. 1990;53(2):81-99. DOI: http://dx.doi.org/10.2307/2786672

32. Newacheck PW, HungYY, Wright KK. Racial and ethnic disparities in access to care for children with special health care needs. Ambul Pediatr. 2002;2(4):247-54.

33. Campanelli, Richard M: Addressing racial and ethnic health disparities. Am J Public Health. 2003;93(10):1624-6. 


\section{Resumo}

Disparidades raciais nos resultados de saúde, acesso a cuidados de saúde, cobertura de seguro e qualidade de atendimento nos Estados Unidos existem há muitos anos. O desenvolvimento e a implementação de estratégias efetivas para reduzir ou eliminar as disparidades de saúde são dificultadas pela nossa incapacidade de avaliar com precisão a extensão e os tipos de disparidades de saúde devido à disponibilidade limitada de informações específicas de raça / etnia, confiabilidade limitada dos dados e informações existentes. e a crescente diversidade da população americana. Variações na classificação racial e étnica usadas para coletar dados dificultam a obtenção de índices confiáveis e precisos de indicadores de saúde e, em alguns casos, causam viés na estimativa de medidas de saúde específicas de raça / etnia. Em 1978, o Escritório de Administração e Orçamento (OMB) publicou a "Diretriz 15" intitulada "Normas Raciais e Étnicas para Estatísticas Federais e Relatórios Administrativos" e forneceu um conjunto de diretrizes claras para classificar as pessoas por raça e etnia. O acesso a cuidados de saúde, factores comportamentais e psicossociais, bem como diferenças culturais, contribuem para as variações raciais e étnicas que existem na saúde de uma pessoa. Para ajudar a eliminar as disparidades de saúde, devemos garantir a igualdade de acesso aos serviços de saúde, bem como a qualidade do atendimento. Os prestadores de cuidados de saúde devem tornar-se culturalmente competentes e compreender as diferenças existentes entre as pessoas que servem para eliminar as disparidades. O aprimoramento dos sistemas de coleta de dados é essencial para desenvolver e implementar intervenções direcionadas para lidar com problemas específicos da população. O desenvolvimento de programas abrangentes e multiníveis para eliminar as disparidades na atenção à saúde exige coordenação e colaboração entre os setores público, privado e profissional (departamentos de saúde locais, estaduais e federais), privados (empresas de seguro-saúde, provedores privados de saúde) e profissionais (médicos e enfermeiros), farmacêuticos, laboratórios, etc).

Palavras-chave: seguro de saúde, profissionais, prestadores de cuidados de saúde privados.

${ }^{\oplus}$ The authors (2018), this article is distributed under the terms of the Creative Commons Attribution 4.0 International License (http:// creativecommons.org/licenses/by/4.0/), which permits unrestricted use, distribution, and reproduction in any medium, provided you give appropriate credit to the original author(s) and the source, provide a link to the Creative Commons license, and indicate if changes were made. The Creative Commons Public Domain Dedication waiver (http://creativecommons.org/publicdomain/zero/ $1.0 /$ ) applies to the data made available in this article, unless otherwise stated. 